caused excessive dissociation which made comparison of the spectra difficult, while smaller currents gave less excitation and therefore reduced the shift of relative intensities.

Snapshots of the absorption spectrum taken at different intervals after the discharge was interrupted showed that the increase perceptibly persisted for at least a thirtieth of a second. Under the conditions of the experiment, this corresponded to seven thousand collisions between iodine molecules. This gave a direct spectroscopic confirmation of the hypothesis of the persistence of vibration in collisions proposed by Herzfeld and Rice in their theory of the dispersion of sound.

The method described here offers the advantage of giving the most direct evidence for the persistence of vibration in collisions. However, it does not lend itself to a quantitative treatment as well as the dispersion of sound method. The reason is that each vibrational level above the normal level not only loses concentration by the general slow approach to the thermal distribution, but at the same time it registers a certain gain coming from higher vibrations. We observe a difference of two effects that cannot easily be treated quantitatively.

In conclusion, the author takes great pleasure in expressing his gratitude and appreciation to Professor O. Oldenberg, who proposed and guided this investigation, for his cooperation and encouragement. He wishes also to acknowledge his indebtedness to Professor E. Leon Chaffee and to Dr. W. M. Preston for their helpful suggestions, and to Mr. H. L. Leighton for his excellent glass blowing.

\title{
The Equilibrium Dissociation and Thermodynamic Constants of Nitrosyl Chloride. Comparison with Spectroscopic Data
}

\author{
Carrol M. Beeson and Don M. Yost \\ California Institute of Technology, Pasadena, California
}

(Received September 6, 1938)

\begin{abstract}
Careful measurements of the equilibrium dissociation of nitrosyl chloride into nitric oxide and chlorine have been made in the temperature range 100-220. Pressure-temperature measurements at $0^{\circ}-100^{\circ}$ on mixtures of nitrosyl chloride and nitric oxide were made and from them the second virial coefficients of nitrosyl chloride gas were calculated. These vary from -389 $\mathrm{cm}^{3} /$ mole at $0^{\circ}$ to $-196 \mathrm{~cm}^{3} /$ mole at $100^{\circ}$. The virial coefficients were used to correct the measured equilibrium constants to those for perfect gases. Equations for free energy, entropy and heat content changes accompanying the dissociation were derived as functions of the temperature. The experimentally found entropy changes for the reaction were found to be less than those calculated from spectroscopic data by $3.61 \pm 0.3 \mathrm{cal} . / \mathrm{deg}$. To attain agreement, the spectroscopic entropy of nitrosyl chloride must be increased by $1.8 \mathrm{cal} . / \mathrm{deg}$, and this was attained by assuming that an observed infra-red frequency at $923 \mathrm{~cm}^{-1}$ is a combination, $633+290 \mathrm{~cm}^{-1}$. For the reaction $2 \mathrm{NOCl}(\mathrm{g})=2 \mathrm{NO}(\mathrm{g})+\mathrm{Cl}_{2}(\mathrm{~g}), \Delta F^{\circ}{ }_{298}=9,720 \pm 60 \mathrm{cal} ., \Delta S^{\circ}{ }_{298}$ $=28.0 \pm 0.5 \mathrm{cal} . / \mathrm{deg} . \Delta H^{\circ}{ }_{298}=18,060 \pm 200 \mathrm{cal} . S^{\circ}{ }_{298}(\mathrm{NOCl})=63.0 \pm 0.3 \mathrm{cal} . / \mathrm{deg}$.
\end{abstract}

\section{INTRODUCTION}

$T$ $\mathrm{HE}$ dissociation of nitrosyl chloride, $\mathrm{NOCl}$, into nitric oxide and chlorine under equilibrium conditions has been studied by several investigators, but only the work of Dixon ${ }^{1}$ lays claim to any accuracy. Dixon's results are subject to some uncertainties in the temperature scale

1 Dixon, Zeits. f. physik. Chemie Bodenstein Festband, $679(1931)$. $\left( \pm 2^{\circ}\right)$, the measurements, and the effect of gas imperfections, so that comparisons with the thermodynamic quantities calculated from molecular and spectroscopic data, while suggestive, are not altogether satisfying. Recently, and after the present investigation was nearly completed, Jahn, ${ }^{2}$ employing the electron diffraction results

\footnotetext{
${ }^{2}$ Jahn, J. Chem. Phys. 6, 335 (1938).
} 
of Ketelaar and Palmer ${ }^{3}$ and the infra-red spectrum determined by Bailey and Cassie, ${ }^{4}$ showed that between the predictions of theory and Dixon's measurements there is a discrepancy that seems definitely greater than that caused by errors in the measurements. To account for the discrepancy, Jahn suggested that nitrosyl chloride might exist in a triplet normal state and perhaps also a low lying singlet state so that its calculated entropy could be increased by $R \ln 4$. He made the justifiable assumption that the difficulty does not arise from a lack of precise knowledge concerning nitric oxide and chlorine; the spectroscopic and thermal data for nitric oxide have been analyzed carefully by Johnston and Giauque, ${ }^{5}$ Johnston and Chapman, ${ }^{6}$ and Johnston and Weimer. ${ }^{7}$ The assumption of a triplet state requires that the substance be paramagnetic. Although liquid nitrosyl chloride is known to be diamagnetic, ${ }^{8}$ Beeson and Coryell ${ }^{9}$ made further experiments on the gas and found it to be diamagnetic also. Accordingly no degeneracy of the kind associated with paramagnetism can be invoked in the case of gaseous nitrosyl chloride.

In the present paper are described the results of experiments on the equilibrium reaction

$$
2 \mathrm{NOCl}(g)=2 \mathrm{NO}(g)+\mathrm{Cl}_{2}(g)
$$

in the temperature range $100^{\circ}-220^{\circ} \mathrm{C}$. In order to make the comparison of the results with theory significant, very pure materials were used and accurate measurements were made. Since the gases are not perfect, additional experiments were made to determine the magnitude of the imperfections. As will be shown below, these accurate measurements are not in accord with the predictions of the theory unless one is justified in giving a different interpretation to the infra-red absorption spectrum than that offered by Bailey and Cassie.

\footnotetext{
${ }^{3}$ Ketelaar and Palmer, J. Am. Chem. Soc. 59, 2629 (1937).

${ }^{4}$ Bailey and Cassie, Proc. Roy. Soc. A145, 336 (1934).

5 Johnston and Giauque, J. Am. Chem. Soc. 51, 3194 (1929).

${ }^{6}$ Johnston and Chapman, J. Am. Chem. Soc. 55, 153 (1933).

${ }^{7}$ Johnston and Weimer, J. Am. Chem. Soc. 56, 625 (1934).

${ }^{8}$ Wilson, J. Am. Chem. Soc. 56, 747 (1934).

${ }^{9}$ Beeson and Coryell, J. Chem. Phys. 6, 656 (1938).
}

\section{Preparation of Materials}

Chlorine. Tank chlorine was purified as follows. The gas was passed into ice-cold distilled water until most of the latter had been converted into chlorine hydrate, $\mathrm{Cl}_{2} \cdot 8 \mathrm{H}_{2} \mathrm{O}$. The temperature was then raised to about $10^{\circ}$, and the chlorine evolved, after passing through reagent grade anhydrous calcium chloride, was condensed into weighed glass capsules. The apparatus used was entirely of glass and the chlorine did not come in

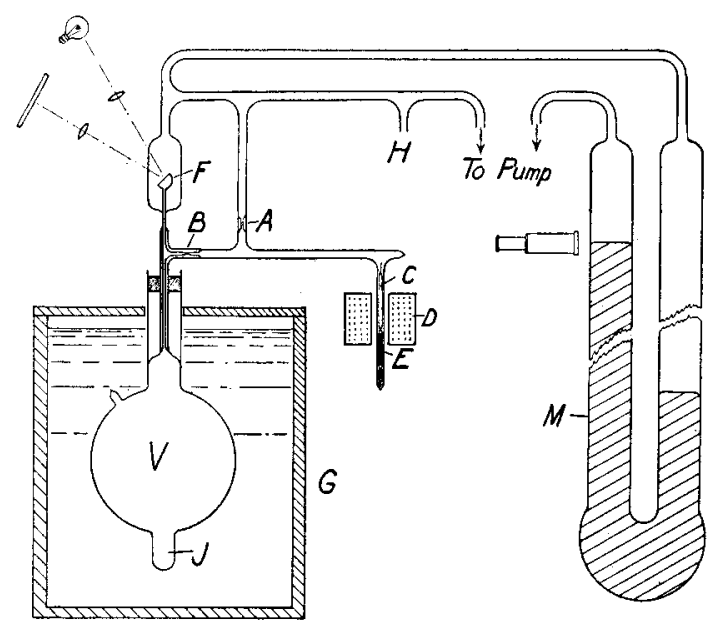

FIG. 1. Reaction vessel and auxiliary apparatus, (not to scale).

contact with rubber or other organic substances. The first portions of chlorine were rejected. Analysis showed that the final product in the sealed glass capsules contained less than 0.1 percent of hydrogen chloride.

Nitric Oxide. The nitric oxide was prepared by a slight modification of the method described by Johnston and Giauque. ${ }^{5}$ The gas was stored at about atmospheric pressure in flasks which had been carefully baked out under vacuum for several hours.

\section{Experimental Methods, Precision of Measurements and Corrections}

\section{Apparatus and procedure}

The apparatus ${ }^{10}$ is shown diagrammatically in Fig. 1. $V$ is a Pyrex glass reaction vessel of $1049.7 \mathrm{ml}$ capacity at $20^{\circ} \mathrm{C}$. $G$ is a thermostat

${ }^{10}$ Blair, Brass and Yost, J. Am. Chem. Soc. 56, 1916 (1934). 
TABLE I. Initial amounts and pressures of reactants. Volume of the reaction vessel, $1049.7 \mathrm{ml}$ : volume of the dead space, $2.3 \mathrm{ml}$ : volume of the side arm, $23.8 \mathrm{ml}$.

\begin{tabular}{|c|c|c|c|c|c|}
\hline \multirow[b]{2}{*}{ RUN } & \multirow[b]{2}{*}{ wr. $\mathrm{gl}_{2}$} & \multicolumn{3}{|c|}{ Nitric Oxide } & \multirow[b]{2}{*}{$\begin{array}{l}\text { APprox. } \\
\text { MoLE RATIO } \\
\text { NO/Cl } / \mathrm{Cl}_{2}\end{array}$} \\
\hline & & $\begin{array}{l}\text { PRESSURE } \\
\text { INT, cm } \mathrm{Cmg} \\
\text { AT } 0^{\circ}\end{array}$ & TEMP. $_{{ }^{\circ} \mathrm{C}}$ & $\begin{array}{c}\text { Vol. } \\
\text { ml }\end{array}$ & \\
\hline III & 0.7397 & 40.51 & 19.95 & 1075.8 & 2.29 \\
\hline IV & 0.8518 & 30.59 & 18.88 & 1075.8 & 1.50 \\
\hline $\mathrm{V}$ & 0.7611 & 37.58 & 22.00 & 1075.8 & 2.04 \\
\hline
\end{tabular}

containing hydrogenated cottonseed oil. ${ }^{11}$ The reaction vessel was attached to a Pyrex glass click gauge ${ }^{2} F$ by means of capillary tubing. The capsule $C$, containing a weighed amount of chlorine, was provided with an easily breakable tip which could be broken off by the glass enclosed, magnetically operated, iron hammer $E$.

Before admitting the gases, the reaction vessel was baked out under high vacuum, allowed to stand evacuated overnight, and again baked out under high vacuum. After cooling, nitric oxide at a convenient pressure was admitted at $H$ and the system sealed off at $A$. With the thermostat at room temperature the pressure of the nitric oxide was measured. The thermostat was then removed and the nitric oxide condensed by means of liquid air into the tube $J$. The chlorine $C$ was frozen by means of liquid air and the tip of the capsule broken. On removing the liquid air the chlorine vaporized and condensed in the tube $J$. Finally the side arm was sealed off at $B$, and the nitric oxide and chlorine were allowed to vaporize into the reaction vessel.

The volumes of the side arm, $23.8 \mathrm{ml}$, and the click gauge and capillary tubing, $2.3 \mathrm{ml}$, were determined at appropriate times and were taken into account in calculating the amount of nitric oxide in the reaction vessel.

The temperature of the thermostat was maintained constant to within $\pm 0.1^{\circ}$ by means of a

\footnotetext{
11 The fumes from hot cottonseed oil have been found to be irritating and possibly harmful to the eyes and lungs. Care should therefore be exercised in the use of this substance.

12 The outer surface of the click gauge was silver-plated. By means of lenses, light was made to converge at the mirror-like surface from which it was reflected to a screen. The reflected pattern varied with the position of the membrane in such a way as to facilitate greatly the use of the gauge. Measurements with the gauge used were reproducible to less than $\pm 0.005 \mathrm{~cm}$.
}

glass-enclosed mercury thermoregulator which contained hydrogen in the space where electrical contact was made or broken. No fouling of the mercury surface occurs in such a regulator if it is carefully freed from oxygen by heating under vacuum before admitting the hydrogen.

Equilibrium pressure measurements were made as follows. Beginning at $100^{\circ}$ the temperature of the thermostat was maintained constant for several hours until it was certain that the pressure in the reaction vessel was undergoing no further change. This pressure was then measured. The temperature of the thermostat was raised $10^{\circ}$ for one hour, then lowered to the original temperature, and the pressure again measured after it had become constant. This procedure was followed at $10^{\circ}$ intervals in proceeding to higher temperatures. In proceeding down the temperature scale, equilibrium was again approached from both the high and low temperature side at each temperature chosen for measurements.

It was found easy to bring the thermostat to any predetermined temperature, and this made it possible, in going down the temperature scale, to carry out measurements at the same temperatures used when going up the scale. Accordingly, for each temperature, four final pressure measurements were made. These did not differ by more than $0.02 \mathrm{~cm}$. The same temperatures were also chosen for the different runs.

\section{Precision of measurements}

The thermoregulator maintained the temperature of the thermostat constant to within $\pm 0.1^{\circ}$. Temperatures were measured to $\pm 0.05^{\circ}$ with mercury thermometers which were calibrated periodically against thermometers from the National Bureau of Standards.

The mercury manometer used had an inside diameter of $2.15 \mathrm{~cm}$. It was enclosed in a case whose front and sides were, respectively, of plate and window glass. Two thermometers served to determine the temperature of the mercury and of the air in the nonevacuated limb. Pressure measurements were made with a cathetometer whose scale was calibrated against a standard decimeter, ruled on glass, from the National Bureau of Standards. Pressure measurements could be duplicated to within $\pm 0.005 \mathrm{~cm}$. 


\section{Corrections applied to all recorded data}

Corrections were made to take account of the following items: (1) the thermal expansion of the Pyrex glass reaction vessel (the coefficient of expansion given in I.C.T. ${ }^{13}$ was used), (2) the exposed stem of the thermometer (stem correction), (3) the almost negligible amount of nitric oxide present in the side arm when it was sealed off, (4) the quite small effect on the pressure caused by changes in temperature of the air in the unevacuated limb of the manometer during measurements, (5) the height of the menisci ${ }^{14}$ and the temperature of the mercury in the manometer, and ( 6 ) the acceleration caused by gravity. ${ }^{15}$

At Pasadena $g=979.57 \mathrm{~cm} / \mathrm{sec}^{2}$. The standard is $g=980.67 \mathrm{~cm} / \mathrm{sec}^{2}$. Accordingly all pressure measurements recorded in the tables are in international centimeters of mercury ${ }^{16}$ at $0^{\circ}$.

In addition to these corrections, correction for the room temperature dead space (obnoxious volume) in the click gauge was also made. To do this it was assumed that the dead space contained only nitrosyl chloride and nitric oxide or chlorine depending on which of these was present in excess. This assumption is justified

${ }^{13}$ International Critical Tables (1929) Vol. II, p. 93.

${ }_{14}$ International Critical Tables (1929) Vol. 1, p. 73.

${ }^{15}$ International Critical Tables (1929) Vol. I, p. 68.

${ }^{16}$ International Critical Tables (1929) Vol. I, p. 69. for correction purposes since at room temperature only some 0.5 percent of the nitrosyl chloride at atmospheric pressure is dissociated. If, in the dead space, $\left(N_{\mathrm{NO}}^{\circ}\right)_{2}$ is the number of moles of $\mathrm{NO}$ plus the number of moles of $\mathrm{NOCl}$, and $\left(\mathrm{N}_{\mathrm{Cl}_{2}}^{\circ}\right)_{2}$ is the number of moles of $\mathrm{Cl}_{2}$ plus half the number of moles of $\mathrm{NOCl}$, then it is easy to show that with excess $\mathrm{NO}$

$$
\left(N^{\circ}{ }_{\mathrm{NO}}\right)_{2}=P V_{2} / R T_{2}
$$

with excess $\mathrm{Cl}_{2}$

$$
\begin{aligned}
\left(N^{\circ}{ }_{\mathrm{NO}}\right)_{2} & =P V_{2} 2 A / R T_{2}(A+2) \\
A & =\left(N^{\circ}{ }^{\circ}\right)_{2} /\left(N^{\circ}{ }_{\mathrm{Cl}_{2}}\right)_{2},
\end{aligned}
$$

where $V_{2}$ is the volume $(2.3 \mathrm{ml})$ of the dead space, $T_{2}$ its temperature, and $P$ the pressure. At each temperature the quantities $\left(N^{\mathrm{o}}{ }_{\mathrm{NO}}\right)_{2}$ and $\left(N_{\mathrm{Cl}_{2}}^{\circ}\right)_{2}$ are subtracted from the initial amounts of nitric oxide and chlorine respectively placed in the reaction vessel.

\section{Results of the Equilibrium Measurements}

Three separate fillings of the reaction flask were made, one with excess nitric oxide, one with excess chlorine and one with equivalent amounts. The initial amounts and pressures are presented in Table I. In Table II are given the observed equilibrium pressures, $P$, in international $\mathrm{cm}$ of $\mathrm{Hg}$ at $0^{\circ}$, and the values of $\log K^{\prime}{ }_{\mathrm{cm}}$ and $\log K_{\mathrm{cm}}$. $K^{\prime}$ was calculated from the following relation

TABLE II. Results of equilibrium measurements. $0^{\circ} \mathrm{C}=273.10^{\circ} \mathrm{K}, K=P_{\mathrm{NO}^{2}} P_{\mathrm{Cl}_{2}} / P^{2}{ }_{\mathrm{NOCl}}$.

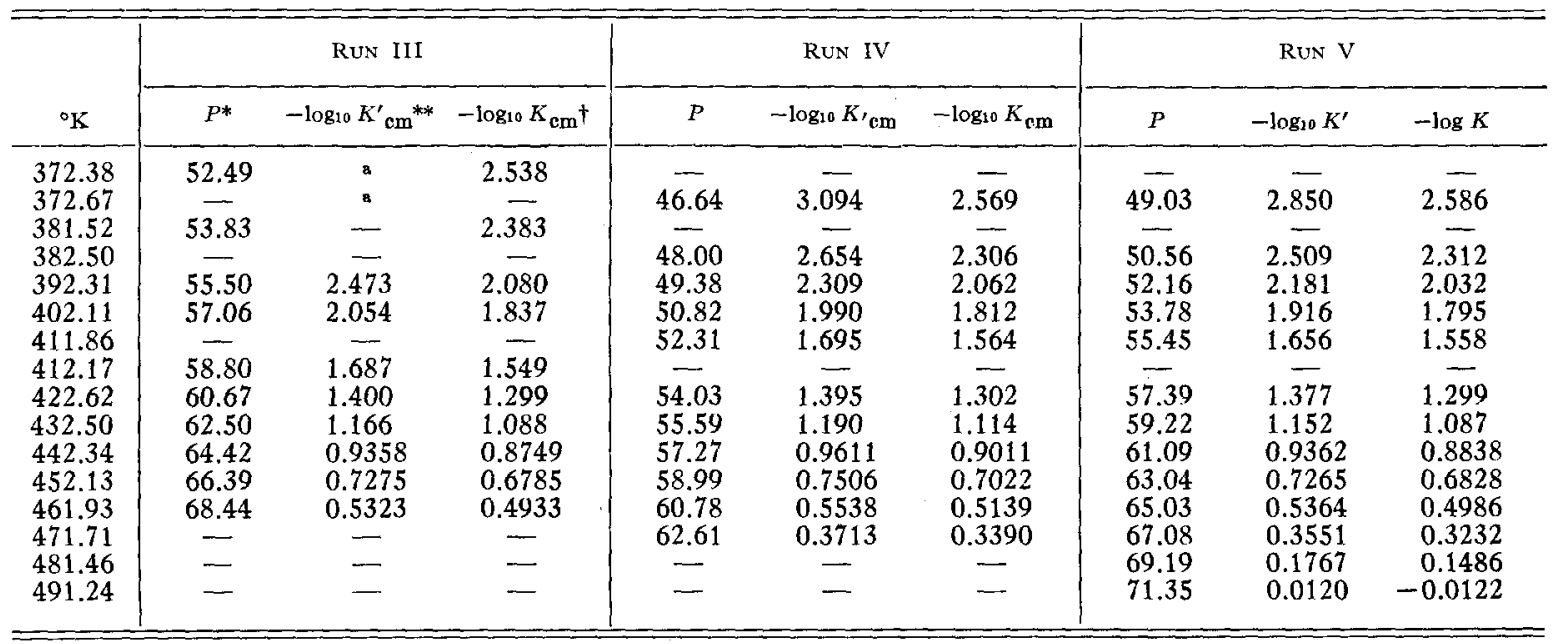

* $P=$ Equilibrium pressures in Int. $\mathrm{cm} \mathrm{Hg}$ at $0^{\circ}$.

** $\log _{10} K^{\prime} \mathrm{cm}$ refers to actual gases.

$+\log _{10} K_{\mathrm{cm}}$ refers to perfect gases.

The values of $\log _{10} K^{\prime} \mathrm{cm}$ are imaginary. 


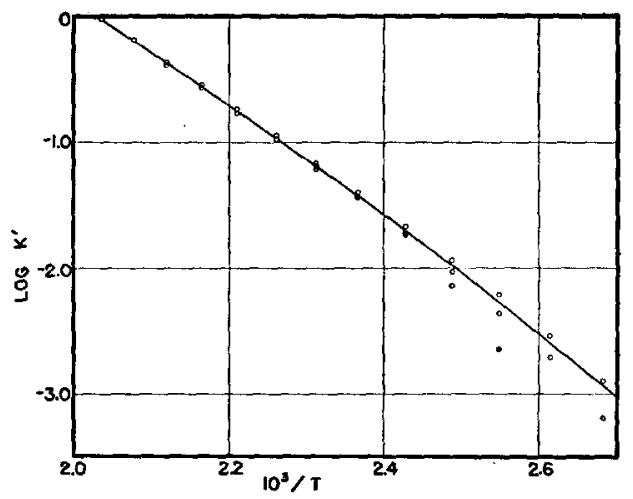

FIG. 2, Plot of $\log K^{\prime}$ (assuming all gases perfect) against $1 / T$.

derived from the perfect gas laws.

$$
K_{\mathrm{cm}}^{\prime}=\left(P_{\mathrm{NO}}^{\circ}-2 \Delta P\right)^{2}\left(P_{\mathrm{Cl}_{2}}^{\circ}-\Delta P\right) / 4 \Delta P^{2},
$$

where $P^{\circ}$ No is the pressure of nitric oxide which would have existed at the temperature in question if no reaction had taken place, $P^{\circ} \mathrm{Cl}_{2}$ is the corresponding pressure of chlorine, and $\Delta P=P^{\circ}{ }_{N O}+P_{\mathrm{Cl}_{2}}^{\circ}-P$. The value of the gas constant used was $R=6236.6 \mathrm{ml} \mathrm{cm} / \mathrm{mole}$ deg. and it was calculated from the I.C.T. ${ }^{17}$ value $R=82.06 \mathrm{ml}$ atmos. $/$ mole deg. Inasmuch as the gases involved are not perfect, additional experiments, to be described below, were made to determine the extent of the imperfections, and the results were used in arriving at $\log K$. $K$ refers, therefore, to perfect gases.

At the higher temperatures the values of $K^{\prime}$ differ from the mean by \pm 3 percent or less. This agreement can be considered as excellent. At the lower temperatures, and when one of the reactants is in excess, considerable difference in the values of $K^{\prime}$ is to be noted. Most of this difference arises from the fact that considerable errors in $P_{\mathrm{Cl}_{2}}$ or $P_{\mathrm{NO}}$, especially when these are small, result from their calculation as differences in large pressures.

If the gases present at the larger pressures were perfect, the errors in $P_{\mathrm{No}}$ or $P_{\mathrm{Cl}_{2}}$ would correspond only to the experimental error, but since the partial pressure of a gas present at a relatively high pressure as calculated from the perfect gas laws is not equal to its true pressure, it follows that a small pressure found by taking the difference between two large pressures will

${ }^{17}$ International Critical Tables (1929) Vol. I, p. 18.

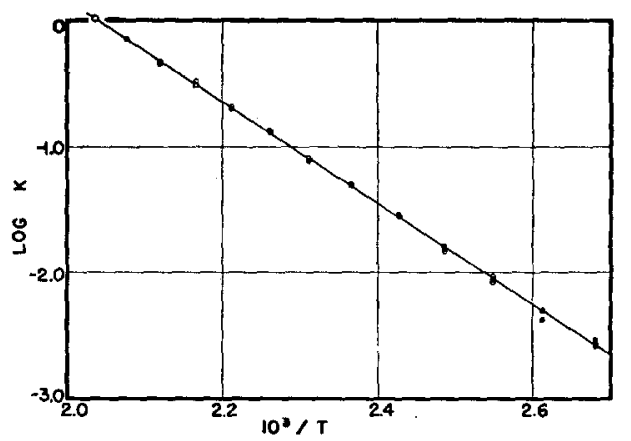

FIG. 3. Plot of $\log K$ (corrected for gas imperfections) against $1 / T$. The solid line was plotted from Eq. (12). Each circle represents one or more experimental values.

be in error by an amount much greater than that of the measurements. The main effect of the corrections for gas imperfection is that on the values of $P_{\mathrm{Cl} 2}$ and $P_{\mathrm{No}}$. At low temperatures the values of $K^{\prime}$ are very sensitive to the corrections and to errors in the measurements; the corresponding values of $K$ are less sensitive since the effect of the corrections for gas imperfections is to make the small uncorrected pressures larger.

For the purposes of thermodynamics the fugacities of imperfect gases must be used in evaluating the equilibrium constants. In the present case it was found, as might be expected, that $K_{f}, K_{p(\text { real) }}$ and $K_{p \text { (ideal) }}$ differed but little. Thus at $422.6^{\circ} \mathrm{C}$ the difference is less than 0.5 percent, well within the allowed error. The correction of the thermodynamic quantities to the ideal gas state is also less than the small experimental errors in these quantities. Accordingly we can consider $K$, which was calculated using corrected pressures, as referring to the ideal gases. In Fig. 2 is shown a plot of $\log _{10} K^{\prime}$ against $1 / T$ and in Fig. 3 the corresponding plot for $\log _{10} K$, where $K$ refers to perfect gases. It will be noted in the latter figure the points for the three runs show but little scattering over the whole temperature range investigated. At $471.74^{\circ}$ Dixon's value for $K^{\prime}$ differs from that in the table by about 7 percent.

\section{Determination OF the Gas IMPERfECTIONS}

The materials and experimental procedure were the same as those in the equilibrium measurements. An excess of nitric oxide was always added to repress the dissociation of the nitrosyl chloride. Over the temperature range $0^{\circ}$ 
to $100^{\circ}$ the pressures of mixtures of accurately known amounts of nitric oxide and chlorine were measured. In Table III are shown the initial amounts and pressures of chlorine and nitric oxide. Table IV contains the observed temperatures and pressures, as well as $\Delta P$ the difference between the observed pressure corrected for the imperfection of nitric oxide, and the pressure calculated for a mixture of perfect gases. Nitric oxide alone shows but little gas imperfection, ${ }^{7}$ and it proved convenient to take this into account in arriving at the values of $\Delta P$. Corrections were also made for the small equilibrium pressure of chlorine present, about 0.01 cm or less.

The equation of state of a pure imperfect gas over a limited range of temperatures and pressures can be taken as

$$
P-N R T / V=N B P / V,
$$

where $B$ is the second virial coefficient and is a function of the temperature. In the correction term on the right $P$ may, to a good approximation, be replaced by $N R T / V$ so that

$$
P-N R T / V=B N^{2} R T / V^{2}=B \bar{N}^{2} R T,
$$

where $\bar{N}$ is the number of moles per unit volume. For a mixture of $n$ imperfect gases $\bar{N}=\bar{N}_{1}+\bar{N}_{2}$ $+\cdots \bar{N}_{n}$. It will be assumed that $B$ is a function of $\bar{N}_{1}, \bar{N}_{2}, \cdots \bar{N}_{n}$ such that the correction term $C=B \bar{N}^{2} R T$ will be given by

$$
C_{1,2} \cdots n=R T \sum_{i}^{n} \sum_{i}^{n} B_{i j} \bar{N}_{i} \bar{N}_{i}
$$

$B_{i j}$ is a measure of the interaction between the $i$ and $j$ molecules, and when $i=j B_{j i}$ is the second virial coefficient for the pure gas $j . B_{i j}$ will be assumed, as seems likely, to be a function of $B_{i i}$ and $B_{j j}$ of such a kind that $B_{i j}$ will be the mean

\begin{tabular}{|c|c|c|c|c|c|}
\hline \multirow[b]{3}{*}{ Rus } & \multicolumn{5}{|c|}{ Vol. SIDE ARM $19.6 \mathrm{mI}$ IN RUN II; $21.4 \mathrm{ml}$ IN RUN IV } \\
\hline & \multirow[b]{2}{*}{ WT. $\mathrm{g}^{\mathrm{Cl}_{2}}$} & \multicolumn{3}{|c|}{ Nitric Oxide } & \multirow[b]{2}{*}{$\begin{array}{c}\text { APPROX. } \\
\text { INITIAL } \\
\text { MOLE RATIO } \\
\text { NO/Cl } / \mathrm{Cl}_{2}\end{array}$} \\
\hline & & $\begin{array}{l}\text { PRESSURE } \\
\text { INT. cm } \mathrm{Hg} \\
\quad \text { AT } 0^{\circ}\end{array}$ & $\begin{array}{l}\text { TEMP. } \\
{ }^{\circ} \mathrm{C} \text {. }\end{array}$ & $\begin{array}{l}\text { Vol. } \\
\text { ml }\end{array}$ & \\
\hline II & 0.6924 & 52.66 & 24.96 & 1071.6 & 3.11 \\
\hline IV & 0.8169 & 58.96 & 27.96 & 1073.4 & 2.92 \\
\hline
\end{tabular}

TABLE III. Initial amounts and pressures of chlorine and nitric oxide. of $B_{i i}$ and $B_{j j}$. Of the various kinds of means, $B_{i j}=\left(B_{i i} B_{j j}\right)^{\frac{1}{2}}$ seems, for physical reasons, less acceptable than $B_{i j}=\left(B_{i i}+B_{i j}\right) / 2$, since in the former case $B_{i j}$ becomes vanishingly small when one of the gases is nearly perfect. The molecules of a gas which, by itself, is nearly perfect may well show appreciable interaction with the molecules of an imperfect gas. Accordingly, the final expression for $C_{1}, 2 \ldots n$ becomes, on dropping superfluous subscripts,

$$
C_{1,2 \cdots n}=\frac{R T}{2} \sum_{i}^{n} \sum_{j}^{n}\left(B_{i}+B_{j}\right) \bar{N}_{i} \bar{N}_{j} .
$$

Johnston and Weimer ${ }^{7}$ have studied the imperfections of nitric oxide and Eucken and Hoff$\operatorname{man}^{18}$ have made a similar study of chlorine. Nitric oxide shows comparatively little imperfection in the temperature range of interest, $B_{\mathrm{NO}}$ being about 10 percent of $B_{\mathrm{Cl}_{2}}$ or $B_{\mathrm{NOCl}}$. For this reason the small imperfections of nitric oxide have already been taken into consideration in the calculation of $\Delta P$ from the experimental data.

Since $B_{\mathrm{NO}}$ is small and $B_{\mathrm{NO}, \mathrm{NOCl}}=\left(B_{\mathrm{NO}}\right.$ $\left.+B_{\mathrm{NOCl}}\right) / 2, B_{\mathrm{NOCl}}=2 B_{\mathrm{NO}}$, NoCl to a good approximation. In Table $\mathrm{V}$ are presented the values of $-B_{\mathrm{NOCl}}$ for even temperatures calculated from

\begin{tabular}{|c|c|c|c|c|}
\hline \multirow[b]{2}{*}{${ }^{\circ} \mathrm{K}$} & \multicolumn{2}{|c|}{ RUN II } & \multicolumn{2}{|c|}{ RuN IV } \\
\hline & $\begin{array}{l}\text { P. INT. } \\
\mathrm{Hg}, 0^{\circ}\end{array}$ & $\begin{array}{l}\Delta P \\
\mathrm{~cm}\end{array}$ & $\begin{array}{l}\text { P. INT, } \\
\mathrm{Hg}, 0^{\circ}\end{array}$ & $\begin{array}{l}\Delta P \\
\mathrm{~cm}\end{array}$ \\
\hline $\begin{array}{l}372.67 \\
348.04 \\
323.09 \\
298.12 \\
276.03\end{array}$ & $\begin{array}{l}66.76 \\
62.32 \\
57.87 \\
53.34 \\
49.35\end{array}$ & $\begin{array}{r}0.25 \\
.28 \\
.27 \\
.32 \\
.35\end{array}$ & $\begin{array}{l}74.10 \\
69.17 \\
64.20 \\
59.20 \\
54.73\end{array}$ & $\begin{array}{r}0.30 \\
.34 \\
.35 \\
.38 \\
.45\end{array}$ \\
\hline
\end{tabular}
smooth curve values of $\Delta P$ under the assumptions

TABLE IV. Results of the experiments to determine

\begin{tabular}{|c|c|c|c|c|}
\hline \multirow{2}{*}{$\frac{\cdot}{t^{\circ} \mathrm{C}}$} & \multicolumn{3}{|c|}{$-B_{\text {NOCI } \mathrm{IN} \mathrm{cm}^{3} / \text { MOLE }}$} & \multirow[b]{2}{*}{$-\mathrm{BCl}_{2}$} \\
\hline & RUN I & RuN II & MEAN & \\
\hline $\begin{array}{r}100 \\
75 \\
50 \\
25 \\
0\end{array}$ & $\begin{array}{l}202 \\
224 \\
260 \\
314 \\
398\end{array}$ & $\begin{array}{l}191 \\
212 \\
245 \\
300 \\
380\end{array}$ & $\begin{array}{l}196 \\
218 \\
253 \\
307 \\
389\end{array}$ & $\begin{array}{l}135 \\
169 \\
215 \\
274 \\
343\end{array}$ \\
\hline
\end{tabular}
gas imperfections.

TABLE V. The second virial coefficients of nitrosyl chloride.

${ }^{18}$ Eucken and Hoffman, Zeits. f. physik. Chemie B5, 442 (1929). 
set forth above. For comparison the values of $-B_{\mathrm{Cl}_{2}}$ are also included in the table. The values of $B_{\mathrm{NOCl}}$ are of the same order of magnitude as those of $B_{\mathrm{Cl}_{2}}$ but larger, and this is to be expected since nitrosyl chloride has the higher boiling point, $-5.7^{\circ}$. The error in $B_{\text {NOCl }}$ is about 7 percent.

The values of $B_{\mathrm{NOCl}}$ were plotted and the plot extrapolated to $200^{\circ}$ (where $B_{\mathrm{NOCl}}=-116 \mathrm{~cm}^{3}$ / mole), and the extrapolated values, together with those for $B_{\mathrm{Cl}_{2}}$ and $B_{\mathrm{NO}}$, were used in connection with Eq. (8) to arrive at the corrections applied to the results of equilibrium measurements. The corrections were made by a process of successive approximations, the second approximation usually sufficing. By far the greater part of the correction is due to the imperfection of nitrosyl chloride since this gas was always present at relatively high pressures.

\section{The Thermodynamic Quantities Calculated FROM THE EXPERIMENTAL RESULTS}

When $\log K$ is plotted against $1 / T$ the resulting curve is, within the limits of error (from less than \pm 3 percent to \pm 4 percent), a straight line. This fact indicates that $\Delta C_{P}$ for the reaction $2 \mathrm{NOCl}(g)=2 \mathrm{NO}(g)+\mathrm{Cl}_{2}(g)$ is small. Since $\Delta C_{P}$ could not be determined from the curvature of the $\log K, 1 / T$ curve, it was evaluated, as a function of $T$, from spectroscopic data. To this end use was made of published data on the heat capacities and entropies of nitric oxide ${ }^{6}$ and chlorine $^{19}$ together with the vibrational frequencies $\left(1888 \mathrm{~cm}^{-1}\right.$ for $\mathrm{NO}, 570 \mathrm{~cm}^{-1}$ for $\mathrm{Cl}_{2}$ ) of these molecules, to construct semi-empirical equations for $C_{P}$. The fundamental nondegenerate frequencies, ${ }^{4} 633 \mathrm{~cm}^{-1}, 923 \mathrm{~cm}^{-1}$ and 1832 $\mathrm{cm}^{-1}$, of nitrosyl chloride were employed to arrive at an expression for $C_{P}$ for this substance. The final result for $\Delta C_{P}$ is

$$
\begin{aligned}
& 2 \mathrm{NOCl}(g)=2 \mathrm{NO}(g)+\mathrm{Cl}_{2}(g) \\
& \Delta C_{P}{ }^{\circ}=8.237-0.021416 T+14.525 \\
& \times 10^{-6} T^{2} \pm 0.01 \mathrm{cal} . / \mathrm{deg} .
\end{aligned}
$$

This yields for $\Delta C_{P}, 3.14 \mathrm{cal} . / \mathrm{deg}$. at $298.1^{\circ} \mathrm{K}$, $1.99 \mathrm{cal} . / \mathrm{deg}$. at $400^{\circ} \mathrm{K}$ and $1.16 \mathrm{cal} . / \mathrm{deg}$. at $500^{\circ} \mathrm{K}$, and shows that, in agreement with experiments, $\Delta C_{P}$ is small.

\footnotetext{
${ }^{19}$ Giauque and Overstreet, J. Am. Chem. Soc. 54, 1731 (1932).
}

From the slope of the $\log K, 1 / T$ curve a value of $\Delta H$ was determined. This when combined with $\Delta C_{P}$ yields the formula

$$
\begin{aligned}
\Delta H^{\circ}=16429+ & 8.237 T-0.010708 T^{2} \\
& +4.8417 \times 10^{-6} T^{3} \pm 180 \mathrm{cal} .
\end{aligned}
$$

Finally the equations for $\Delta F^{\circ}, \log _{10} K$ and $\Delta S$ may be established and are, respectively,

$$
\begin{aligned}
& \begin{array}{l}
\Delta F^{\circ}=16429-18.967 T \log _{10} T+21.452 T \\
+0.010708 T^{2}-2.4208 \times 10^{-6} T^{3} \pm 40 \mathrm{cal} .,
\end{array} \\
& \begin{array}{r}
\log _{10} K_{\mathrm{cm}}=-2.808-3591.0 / T+4.1457 \log _{10} T \\
-0.0023406 T+0.52915 \times 10^{-6} T^{2} \pm 0.02,
\end{array} \\
& \text { and } \\
& \begin{array}{r}
\Delta S^{\circ}=-13.215+18.967 \log _{10} T-0.021416 T \\
\quad+7.2625 \times 10^{-6} T^{2} \pm 0.3 \mathrm{E} . \mathrm{U} .
\end{array}
\end{aligned}
$$

It is to be emphasized that spectroscopic data have been used here only in arriving at an expression for $\Delta C_{P}$. In Fig. 3 the solid curve was plotted from the above equation for $\log _{10} K$; the circles indicate experimental values. The equation, within the limits of error, agrees with experiment throughout the temperature range investigated. Since $\Delta C_{P}$ is small, agreement would still result if this quantity were altered by as much as 50 percent.

From the above equations, and from the published values for the entropies at $25^{\circ}$ of nitric oxide, ${ }^{6} 50.35 \mathrm{cal} . / \mathrm{deg}$. and chlorine, ${ }^{19}$ $53.31 \mathrm{cal} . / \mathrm{deg}$, the following thermodynamic quantities were calculated.

$$
\begin{aligned}
2 \mathrm{NOCl}(g) & =2 \mathrm{NO}(g)+\mathrm{Cl}_{2}(g), \\
\Delta F^{\circ}{ }_{298} & =9,720 \pm 60 \mathrm{cal} . \\
\Delta H^{\circ} & =18,060 \pm 200 \mathrm{cal} . \\
\Delta S^{\circ}{ }_{298} & =28.0 \pm 0.5 \mathrm{cal} . / \mathrm{deg} . \\
S^{\circ}{ }_{298}(\mathrm{NOCl}) & =63.0 \pm 0.3 \mathrm{cal} . / \mathrm{deg} .
\end{aligned}
$$

\section{Comparison with Spectroscopic Data}

The entropies of nitric oxide and chlorine have been calculated from spectroscopic data, by Johnston and Chapman ${ }^{6}$ and Giauque and Overstreet. ${ }^{19}$ From their results the following semi-empirical equations were derived.

$$
\begin{aligned}
& S_{\text {NO }}^{\circ}=7 / 2 R \ln T+S_{1888}+10.787 \text { E.U., } \\
& S_{\mathrm{Cl}_{2}}=7 / 2 R \ln T+S_{570}+13.180 \text { E.U., }
\end{aligned}
$$

where $S_{\omega}$ is the entropy associated with the vibrational frequency $\omega$. 
The moments of inertia of nitrosyl chloride, referred to principal axes, as calculated from Ketelarr and Palmer's ${ }^{3}$ electron diffraction results are, $I_{1}=8.99 \times 10^{-40} \mathrm{~g} \mathrm{~cm}^{2}, I_{2}=146.8 \times 10^{-40} \mathrm{~g}$ $\mathrm{cm}^{2}$ and $Y_{3}=155.8 \times 10^{-40} \mathrm{~g} \mathrm{~cm}^{2}$. The interatomic distances given by them are $\mathrm{N}-\mathrm{O} 1.14 \pm 0.02 \mathrm{~A}$, and $\mathrm{Cl}-\mathrm{N} 1.95 \pm 0.01 \mathrm{~A}$, and the bond angle $\mathrm{Cl}-\mathrm{N}-\mathrm{O}$ is $116 \pm 2^{\circ}$. Bailey and Cassie's ${ }^{4}$ infrared study led them to the conclusion that the fundamental frequencies of nitrosyl chloride were $\omega_{1}=1832 \mathrm{~cm}^{-1}, \omega_{2}=633 \mathrm{~cm}^{-1}$ and $\omega_{3}=923 \mathrm{~cm}^{-1}$. $\omega_{2}$ represents the bending frequency. From these data there was derived the relation

$$
\begin{aligned}
S_{\mathrm{NOCl}}^{\circ}=4 R \ln T+S_{633}+ & S_{923} \\
& +S_{1832}+15.460 \text { E.U. }
\end{aligned}
$$

and finally the purely empirical relation

$$
\begin{aligned}
& \Delta S \text { (spectr. }=-9.605+18.967 \log _{10} T \\
& -0.021416 T+7.2625 \times 10^{-6} T^{2} \pm 0.01 \text { E.U. }
\end{aligned}
$$

The experimentally found relation is

$$
\begin{aligned}
& \Delta S \text { (expt.) }=-13.215+18.967 \log _{10} T \\
& \quad-0.021416 T+7.2625 \times 10^{-6} T^{2} \pm 0.3 \text { E.U. }
\end{aligned}
$$

A comparison of the spectroscopic and experimental values of $\Delta S$ shows immediately that

$$
\Delta S \text { (spect.) }-\Delta S \text { (expt. })=3.61 \pm 0.3 \text { E.U. }
$$

that is, a discrepancy of $3.61 \pm 0.3 \mathrm{cal} . / \mathrm{deg}$. which is, within the limits of error, independent of the temperature. This is much larger than could possibly be accounted for by experimental error. It is smaller, but of the same order of magnitude as that calculated by $\mathrm{Jahn}^{2}$ using Dixon's ${ }^{1}$ measurements, namely $5.673 \mathrm{cal} . / \mathrm{deg}$.

There seems to be no escape from the assumption that the analyses of the spectroscopic data for nitric oxide and chlorine are correct. Accordingly, the discrepancy is caused by some uncertainty in the spectroscopic data for nitrosyl chloride, or its energy levels are degenerate as a result of some unknown factor. The former possibility only can be considered here. The discrepancy is such that the entropy of nitrosyl chloride calculated from spectroscopic data is too small. Consideration must be given to factors that would increase it by $\frac{1}{2} 3.6=1.8 \mathrm{E}$.U.

The interatomic distances of Ketelaar and Palmer cannot be increased greatly without making them improbably large. The $\mathrm{Cl}-\mathrm{N}$ distance of $1.95 \mathrm{~A}$ is, according to these authors, already larger by $0.26 \mathrm{~A}$ than that to be expected. A change in the bond angle from $116^{\circ}$ to the improbably small value of $90^{\circ}$ increases $S_{\text {NOC1 }}^{\circ}$ by only 0.3 E.U. Accordingly it does not seem likely that the discrepancy results from uncertainty in the size or shape of the molecule.

It is possible that not all of the frequencies reported by Bailey and Cassie are fundamentals. The frequency $1832 \mathrm{~cm}^{-1}$ is, as is to be expected, nearly equal to that found with nitric oxide, $1888 \mathrm{~cm}^{-1}$, and hence is, in all probability, a fundamental. The following considerations indicate that the $923 \mathrm{~cm}^{-1}$ frequency is not a fundamental. Lechner ${ }^{20}$ has derived formulas for the fundamental frequencies of unsymmetrical triatomic molecules as a function of the force constants for stretching and bending. The force constants for the $\mathrm{N}=\mathrm{O}$ and $\mathrm{N}-\mathrm{Cl}$ bonds may be evaluated from Badger's Rule ${ }^{21}$ and were found to be $k_{12}=15.0 \times 10^{5}$ and $k_{23}=1.6 \times 10^{5}$ dynes $/ \mathrm{cm}$, respectively. Two of Lechner's relations take the following forms:

$$
\begin{aligned}
\omega_{1}^{2}+\omega_{2}^{2}+\omega_{3}^{2}=35.92 \times 10^{5}+6.01 d, \\
\omega_{1}^{2} \omega_{2}{ }^{2} \omega_{3}{ }^{2}=346 \times 10^{10} d,
\end{aligned}
$$

where $d$ is the bending force constant and $\omega_{1}, \omega_{2}, \omega_{3}$ are frequencies expressed in $\mathrm{cm}^{-1}$. If the molecule were linear the terms $\omega_{2}{ }^{2}$ and $6.01 d$ in the first equation would be absent. With $\omega_{1}=1832 \mathrm{~cm}^{-1}, \omega_{3}$ becomes $490 \mathrm{~cm}^{-1}$. The molecule is not linear but has a bond angle of $116^{\circ}$. The value of $\omega_{3}$ will be somewhat different for the bent model but not greatly so; it seems reasonable then to select the observed frequency $633 \mathrm{~cm}^{-1}$ for $\omega_{3}$. It is now possible to evaluate approximately the bending frequency $\omega_{2}$ and the force constant $d . \omega_{2}$ (calc.) $=346 \mathrm{~cm}^{-1} . d=0.46$ $\times 10^{5} \mathrm{dyne} / \mathrm{cm}$. This value of $\omega_{2}$ is considerably lower than the lowest observed frequencies, namely $633 \mathrm{~cm}^{-1}$ and $923 \mathrm{~cm}^{-1}$. If it is assumed that the greater of these is a combination such that 923 $=633+290$, then the fundamental frequencies for nitrosyl chloride become 1832, 290 and 633 $\mathrm{cm}^{-1}$, respectively. Professor R. M. Badger has called our attention to the fact that further support for the assumption is provided by the low

${ }^{20}$ Lechner, Monatshefte für Chem, 61, $385(1932)$.
${ }^{1}$ Badger, J. Chem. Phys. 2, $128(1934) ; 3,710$ (1935). 
bending frequency ${ }^{22}$ of $397 \mathrm{~cm}^{-1}$ for $\mathrm{Cl}-\mathrm{C} \equiv \mathrm{N}$, a linear molecule that is probably stiffer than $\mathrm{Cl}-\mathrm{N}=\mathrm{O}$. The assumption of the low bending frequency leads to a much smaller discrepancy between theory and experiment, namely

$$
\begin{aligned}
\left.\Delta S^{\circ} \text { (spect. }\right)-\Delta S(\operatorname{expt} .) & =0.40 \text { E.U. at } 100^{\circ} \\
& =0.10 \text { E.U. at } 220^{\circ}
\end{aligned}
$$

and the largest of these values is only slightly greater than the average experimental error, \pm 0.3 E.U. The effect of the lowered frequency on $\Delta C_{P}$ has been taken into account, and the effect on $\Delta H^{\circ}$ and $\Delta F^{\circ}$ is found to be less than the experimental error.

Another possible interpretation of the infra-red spectrum is that both the $923 \mathrm{~cm}^{-1}$ and $633 \mathrm{~cm}^{-1}$ bands are first harmonics. The fundamentals would then be 1832,317 and $462 \mathrm{~cm}^{-1}$, respectively. This interpretation would be in accord with the considerations based on Lechner's formulas. The discrepancy between the spectro-

22 Sutherland, Proc. Roy. Soc. A156, 654 (1936). scopic and experimental entropy changes is reduced to $0.30 \mathrm{cal} . / \mathrm{deg}$. at $220^{\circ}$ and to 0.80 cal./deg. at $100^{\circ}$. This result is not as satisfactory as that obtained through the assumption that $923=633+290 \mathrm{~cm}^{-1}$.

The discrepancy reported by Jahn is to a large extent removed if the assumption of the lowered frequency is made. That it is not wholly removed may possibly be ascribed to the experimental errors in Dixon's results.

The possibility of finding some new and interesting kind of degeneracy should not, of course, be overlooked. Before ascribing the discrepancy to such a cause a further investigation of the infra-red spectrum of nitrosyl chloride should be made, or its heat capacity determined. Because of the intense red color of the substance it has not been found possible to obtain its Raman spectrum. ${ }^{23}$ The tentatively predicted frequency of about $290 \mathrm{~cm}^{-1}$ falls in the infra-red region at $30-40 \mu$.

${ }^{23}$ Dadieu and Kohlrausch, Physik. Zeits. 33, 165 (1932).

\title{
On the Viscosity of Nonpolar Liquids
}

\author{
S. Kyropoulos* \\ California Institute of Technology, Pasadena, California
}

(Received September 30, 1938)

\begin{abstract}
The phenomenon of viscosity drop by flow-orientation (i.e., mechanical orientation in a Couette apparatus) with nonpolar liquids composed of large dissymmetrical molecules points to a marked influence of the dissymmetry of polarizability on this phenomenon and on viscosity in general. In the case of such liquids the molecular forces of interaction are practically confined to the dispersion forces, and there are very definite states of minimum mutual potential energy. This condition results in temporary formation of complexes of higher saturation of those residual fields of force which interact in the phenomenon of viscosity. An analogous case is represented by long chain hydrocarbon molecules with polar head where the dipole forces are eliminated to a great extent, insofar as viscosity is concerned, by association, resulting in a viscosity behavior very similar to that of corresponding paraffins. With small molecules, even small permanent moments tend to suppress the influence of the anisotropy of polarizability of deformation, resulting in a type of complex which is ultimately, even temporarily, more determined by the dipole forces.
\end{abstract}

$\mathrm{T}$ HE present attempt of examining the factors which determine the viscosity of nonpolar liquids has its origin in an engineering problem treated some years ago, relating to the theory of lubrication.

\footnotetext{
* Research fellow.
}

Starting with the fundamental equation of Newton, (1) $F=\eta_{T} \cdot A \cdot \partial u / \partial h$ in which $F$ is the frictional force, $A$ an area (the lubricated area), $\eta_{T}$ the absolute viscosity and $\partial u / \partial h$ the gradient of shear between two lubricated faces of a bearing of infinite length in motion, Osborne Reynolds 